\title{
Extending the HELP approach through the system harmonisation philosophy\#
}

\author{
Shahbaz Khan* \\ Division of Water Sciences, Natural Sciences Sector, UNESCO, 1, rue Miollis, 75732 Paris cedex 15, SP France
}

\begin{abstract}
The sustainable management of the water resource will become more and more important as population demands and environmental custodianship awareness grows. The Hydrology for the Environment, Life and Policy (HELP) program aims to bring together scientific research in catchment management with practical application of policy and on-ground management practices. This paper builds on an existing foundation of knowledge and exposure, within the Murrumbidgee HELP catchment already recognised as a leader finding real solutions while working with multiple stakeholders. The HELP program has now moved into the implementation stage and includes 67 catchments from around the world that are looking to better utilise their water resources for sustainable communities. Of those 67 basins there are 7 demonstration basins, one of which is the Murrumbidgee. There is a need for extending HELP to non-HELP basins through lessons learnt from existing efforts. In this context System Harmonisation Framework is introduced as an integrative framework for extending HELP in irrigated catchments across the globe.

The 'System Harmonisation' philosophy seeks to identify business opportunities for irrigators to become an integral part of an expanding environmental services industry and in so doing support a truly sustainable and diversified irrigation business environment. A good understanding of system wide harmonisation can be gained from how irrigation systems are linked with the catchment water cycle and how life support systems and regional economies depend on them. The system harmonisation framework involves an all encompassing approach that combines research and business principles to achieve productive and environmental improvements at the catchment level. The framework involves five feasibility steps including three research components and a business analysis component: The research components comprise analysis and characterisation of hydrologic systems, water productivity, markets and ecosystem services, and mechanisms and processes for change. The business component is based on the formation of Regional Irrigation Business Partnerships (RIBP) to explore and implement opportunities for improved productive and/or environmental outcomes through changes in water management. The system harmonisation process establishes the base physical, economic and social position of the region, identifies the key pressure points in the system and the system constraint. System harmonisation thus offers great opportunity for extending HELP to other catchments around the globe to enhance the multifunctional productivity of water resources.
\end{abstract}

Keywords: environmental services, multifunctional water productivity, sustainability, system harmonisation

\section{Introduction}

HELP is a joint initiative of the United Nations Educational Scientific and Cultural Organisation (UNESCO) and the World Meteorological Organisation (WMO). HELP began following the $5^{\text {th }}$ UNESCO/WMO International Conference on Hydrology in February 1999 and is led by the International Hydrology Program. HELP aims to address key water resource issues in the field and integrate them with policy and management needs therefore introducing a new approach to integrated catchment management. The new approach is to use real catchments, with real water related problems as the environment within which hydrological scientists, water resources managers and water law and policy experts can work together.

Internationally there is a major lag between research and management policy since most water management policy is based on outdated knowledge and technology and there is a paradigm lock between water scientists and policy makers (Fig. 1).

\# Revised paper. Originally presented at the symposium 'HELP in Action: Local Solutions to Global Water Problems - Lessons from the South' which was held at the Emperor's Palace, Johannesburg, South Africa from 4 to 9 November 2007.

* To whom all correspondence should be addressed.

++331456845 69; fax: +331456858 11;

e-mail: s.khan@unesco.org

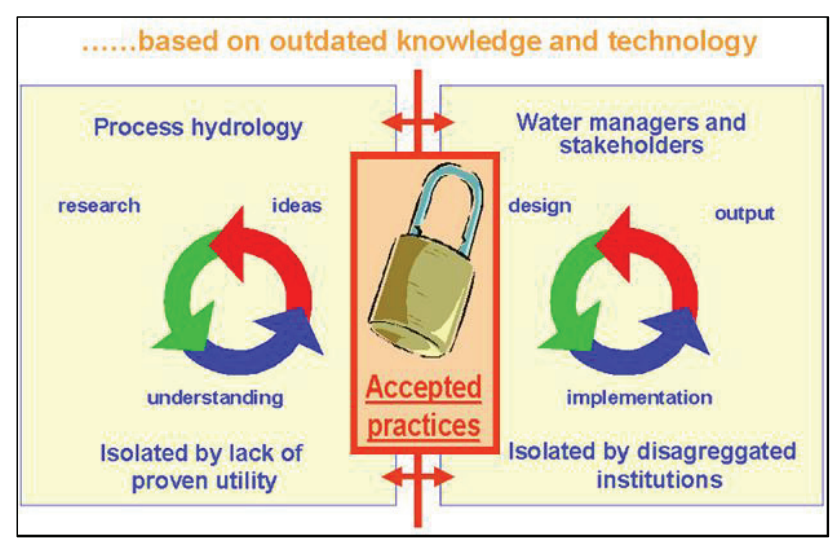

Figure 1

Paradigm lock between scientists and policy makers (Falkenmark, 2004)

In many basins stakeholders are unaware of what technical facilities are available and scientists do not appreciate how to become part of real solutions. HELP initiative is aimed to bridge the gap between the water policy, water resource management and scientific communities from the setting of research agenda to the free flow of information for use in management and policy making. 


\section{Global HELP perspectives}

HELP is founded on a global network of catchments. National or local authorities can suggest catchments to be included, which will need to fulfil the HELP criteria for baseline physical and socio-economic data exchange. A new catchment must also have adequate local capacity to increase sharing of expertise, to improve access to data and the findings from other HELP catchments, and to provide opportunities for funding and building capacity in water institutions.

The HELP catchments are distributed between the developed North (North America and Europe) and the South (rest of the world) in the approximate ratio 40:60 (Fig. 2). The basins reflect a vast range of geographic and demographic properties, from the Aral Sea basin with 5 countries $\left(1.6 \mathrm{~m} . \mathrm{km}^{2}\right.$ and population $42.5 \mathrm{~m}$.) to the Talise basin in Vanuatu covering $6 \mathrm{~km}^{2}$ and 400 people. Eight basins were larger than $1 \mathrm{~m} . \mathrm{km}^{2}$ and nine were smaller than $1000 \mathrm{~km}^{2} .23$ basins had populations of greater than 1 million and 11 basins had populations of lower than 100 000. This is a remarkably diverse set of river basins, providing a unique range of challenges and opportunities for developing good governance and integrated water resource management (IWRM) globally. Table 1 shows the distribution of basins by region and the final classification.

The demonstration and operational basins each have several years of practical experience of working within the HELP framework. In some cases longstanding scientific programmes have been developing further through the application of sustainability and good governance. The HELP initiative provides them with international recognition of progress achieved in this new direction. The high proportion of operational basins in Europe is a result of developments in the European Union. Many of these projects have benefited from EU funding, or national funding linked to EU legislation. Most projects in the South are linked to local recognition that water problems are best approached through IWRM. Currently HELP basins are exploring twining opportunities to share their experiences in integrated water resources management. Further information about individual HELP basins can be found at www.unesco.org/water/ihp/help.

\section{HELP action areas}

Gibbons et al. (1994) distinguishes two approaches to knowledge production: the traditional research is Mode 1, in which there are narrow fields of study and separate roles, with academics developing the knowledge and passing it on to the practitioners. In Mode 2, knowledge is produced by a crossdisciplinary team that includes the practitioner, and the learning is immediate for all - it is part of the discovery process. The role of the practitioner is central to Mode 2 throughout the entire research process. The HELP initiative is encouraging Mode 2 knowledge generation. HELP is designed to develop

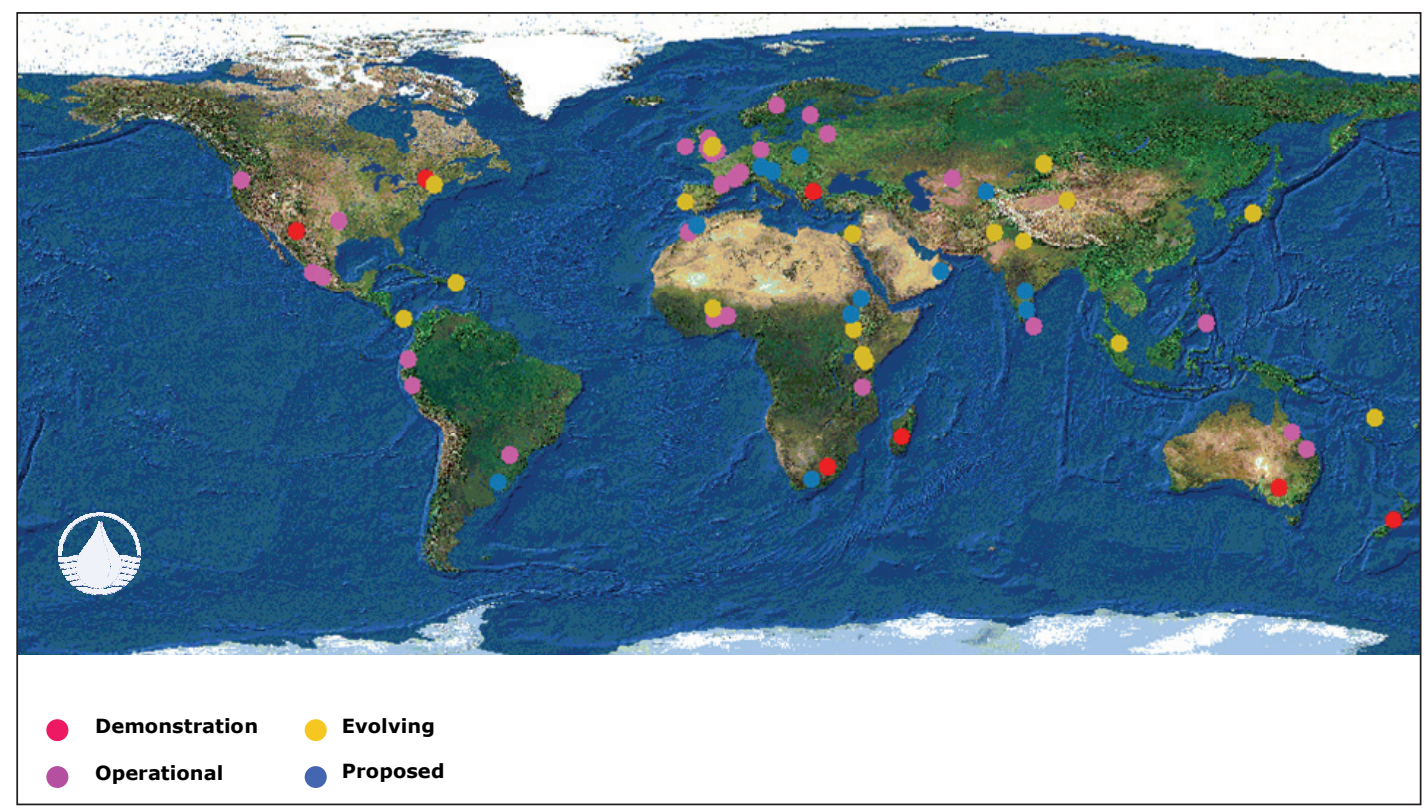

Figure 2

Current UNESCO HELP Basins

\begin{tabular}{|l|c|c|c|c|c|}
\hline \multicolumn{7}{|c|}{ Regional classification of HELP basins } \\
\hline Region & $\begin{array}{c}\text { Basins } \\
\text { total }\end{array}$ & $\begin{array}{c}\text { Demon- } \\
\text { stration }\end{array}$ & $\begin{array}{c}\text { Opera- } \\
\text { tional }\end{array}$ & Evolving & Proposed \\
\hline North America & 7 & 2 & 2 & 2 & \\
\hline Central and South America & 7 & & 5 & 1 & 1 \\
\hline Europe & 21 & 1 & 11 & 5 & 3 \\
\hline Africa & 12 & 2 & 2 & 4 & 4 \\
\hline Middle East & 2 & & & 1 & 1 \\
\hline Asia & 13 & & 4 & 6 & 3 \\
\hline Australasia & 5 & 2 & 2 & 1 & \\
\hline Total & $\mathbf{6 7}$ & $\mathbf{7}$ & $\mathbf{2 6}$ & $\mathbf{2 0}$ & $\mathbf{1 2}$ \\
\hline
\end{tabular}


scientific research in the application of IWRM through Hydrology for Environment, Life and Policy (IHP, 2001). Examples of HELP success in active involvement of university teaching, policy-making and facilitating (water and land resource managers groups) to set the policy agenda and ensure the scientific results will benefit societal needs through the revision of policy and management practices in Australia are given by Khan (2004).

HELP has currently six major action areas for promotion of Mode 2 science as described below.

\section{Water and climate}

The major research question into water and climate area is: 'How can knowledge, understanding, and predictive modelling of the influence of global variability and change on hydrological variables and remotely sensed data be used to improve the management and design of water resource, agro-hydrological and eco-hydrological systems?'

Subsidiary issues for this interest area include:

- How significant is the relationship between the statistics of hydrological variables and observable global phenomena, and how does this change with location?

- How can remote data capture, and advanced information transfer technologies best be applied to improve the management and design of water systems?

- How can predictions of seasonal to inter-annual variations be used to improve the management of water, including for disaster prevention (floods and droughts)?

- How significant are multi-decadal fluctuations in climate, and how can knowledge of such fluctuations be used to improve the design of water systems?

- What is the hydrological significance of potential anthropogenic climate change, and how can predictions of such change best be used to improve design of water systems?

\section{Water and the environment}

The level of environmental protection to be provided in any basin is a matter of political choice and commitment. Developing countries will usually be least able or willing to consider the issue of the water required for environmental protection - their first priority usually is to take care of the immediate, basic needs of their population. This HELP initiative is aimed to raise the awareness so that these two objectives are not contradictory and there are pathways to strike a balance. Major issues include the potential impacts on the environment of:

- Population growth

- Industrialisation and pollution

- Land cover/land-use changes

- Species extinction and introduction of new species perceptions and attitudes of society towards the environment.

HELP research questions include:

- What role does the environment play in securing water resources?

- How do we place a value on the 'natural' environment?

- How can we identify the impacts of environmental change on water resources?

- How do we minimise conflicting environmental and human requirements?

- What is the effectiveness of environmental law on water resources?

\section{Water quality and human health}

This HELP objective aims to develop the necessary integrated view of how catchments work, in order to understand the relations between water quality and water quantity at variable spatial and temporal scales. There is need to understand how water quality is affected by varying land uses and management approaches - that is, to understand the basic evolution of water quality. The understanding of processes linked with contaminant transfer and temporary adsorption (or absorption) through the land system - before these enter into rivers and streams - is extremely poor. HELP aims to promote appropriate water-quality monitoring programmes in its network of basins.

\section{Water and food}

The major HELP challenge in terms of water and food is 'how can the efficiency with which water is used in agriculture be improved and how do the need, scope and methods for achieving this vary regionally and locally?

HELP is aiming to facilitate research on some of the following questions:

- The most appropriate techniques for reducing water losses from agricultural fields due to surface runoff, soil evaporation and drainage

- How much water could be saved by improving transpiration, and what techniques can be used to do this

- How much water efficiency could be improved by using different crops and/or crop mixtures

- The relative savings to be made in rain-fed and irrigated agriculture, and potential for the complementary use of water between the two

- Whether significant efficiency gains can be made through assessing the way water can be used in different places and at different times across an entire catchment

- The downstream impacts of increasing water-use efficiency in agricultural areas

- The reasons local farmers do not adapt apparently straightforward technologies for improving water-use efficiency.

\section{Water and conflicts}

HELP includes a component on the role of hydrological data, information and process understanding in management of water resources, as well as in co-operation on water management and avoidance and resolution of conflicts.

HELP aims to promote development and application of alternative dispute resolution (ADR) techniques to water management through:

- Studying the role of hydrological information in creating the basis for rational management of water by a nation and among neighbouring countries

- Encouraging basic studies of conflict management integrated with a research programme that has the necessary databases linked with process hydrology

- Supporting studies of specific cases in selected river basins

- Conducting real-world simulations in support of joint management.

\section{Improving communications}

HELP aims to encourage multilevel stakeholder engagement to:

- Provide a reduced set of reliable and comparable information on the state of catchments 
- Interpret science in a way useful to managers

- Include water resources, environment, social and economic criteria

- Capture the 'essence' of the catchment in a few statistics

- Provide comparison between countries and regions

- Indicate trends over time and space

- Measure success (and failure) of catchment management, programmes and policies

- Ensure comparability between projects.

Participants from the partner basins at the HELP Symposium at Kalmar, Sweden (18-22 August 2002) identified the lack of the following elements to wider societal acceptance of hydrology research:

- Awareness of issues/ownership/stakes

- Adequate information

- Appropriate communication/liaison strategy

- Reciprocal trust and transparency

- Overall engagement

- Common level of operation

- Direct relevance to stakeholders and issues

- Formal and informal education at different levels

- Local people to convey project results

- Identification of stakeholders.

A number of HELP strategies such as assessment of communication needs before the start of a HELP project were identified to overcome societal acceptance barriers to help achieve integration of community aspirations with scientific research.

\section{Extending HELP through system harmonisation framework}

The UNESCO HELP covers 67 catchments around the globe. Of those 67 HELP basins there are currently 7 demonstration-grade basins, one of which is the Murrumbidgee basin-the first global reference catchment. Like many other catchments, irrigation and environmental sustainability in the Murrumbidgee catchment have to date been managed as two competing enterprises under separate and divergent control. This orthodoxy has often translated into polarised approaches to resource management to the detriment of both production and environmental sustainability. In Australia there is an increasing quest and support for a 'harmonised' business philosophy to sustainable use of land and water resources to achieve enduring business partnerships in water management (Khan et al., 2008).

This approach seeks to identify business opportunities for irrigators to integrate them into an expanding environmental services industry and in so doing support the expansion of a truly sustainable and diversified irrigation business environment. This concept is based on improving irrigation-based businesses by establishing enduring business partnerships that connect irrigators with environmental services, as well as boost the multifunctional productivity of water.

The system harmonisation concept can be defined as:

$$
\begin{aligned}
& \text { 'A strategy to improve cross-organisational } \\
& \text { communication and system-wide management to } \\
& \text { improve production and environmental outcomes } \\
& \text { in a whole of catchment context.' }
\end{aligned}
$$

The idea behind this concept entails considering irrigation systems as an integral part of the catchment landscape as well as the regional economic and governance system. This framework acknowledges that various entities within the system are interlinked and that a unified or harmonised approach across subsystems becomes inevitable if system-wide productivity is to be optimised and if win-win outcomes for all stakeholders are to be achieved. A good understanding of system-wide harmonisation can be gained from Fig. 3 .

Water resource systems involve many subsystems, all of which are intrinsically linked to one another, not only physically, but also with the environment and to the economy and the society in which they exist. In addition to establishing the base physical, economic and social position of an irrigation scheme in the region, some of the key pressure points in the system and the constraints they impose need to be identified if system harmonisation is to be achieved. In particular, these relate to the capacity to optimise on-farm and near-farm irrigation system performance and water demand patterns to deliver productive and environmental dividends. It should be noted that the key pressure points in a system are not necessarily physical or biophysical. These pressure points can also be of an economic, social, environmental or institutional disposition. The mix of structural and non-structural measures is likely to be system specific, given the diversity of issues within each system (Bonell and Koontz, 2007).

The focus of system harmonisation is to assess, in a comprehensive and systematic way, the changes in these key pressure

New science for synchronising irrigation systems with their operating environments and providing ecosystem services

Business cases and delivery templates
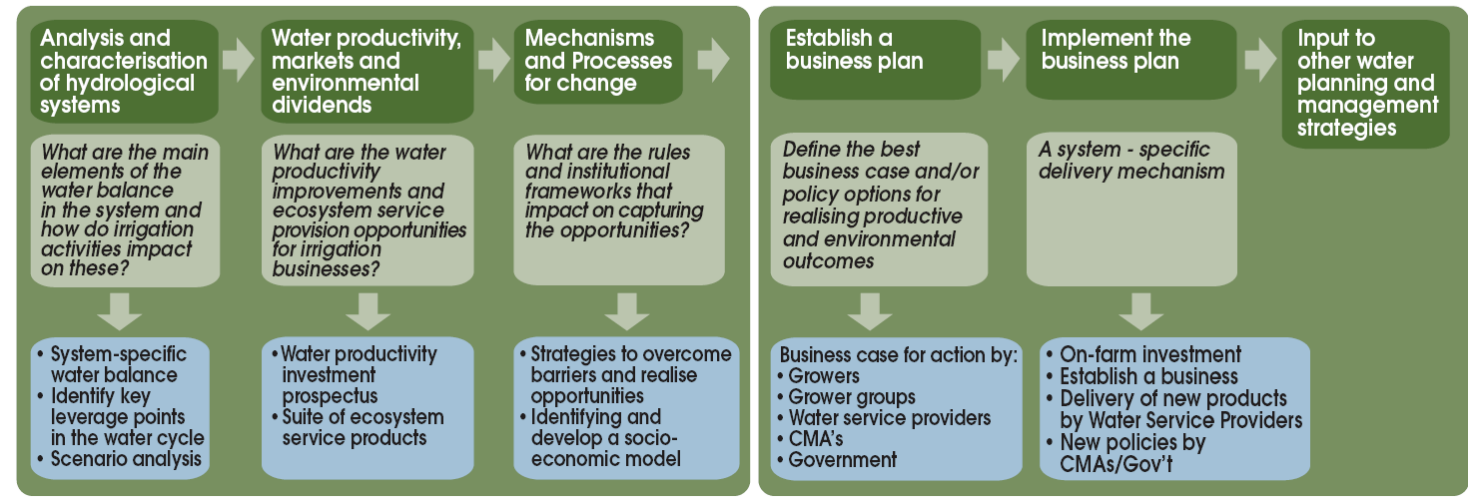

Figure 3

Five way feasibility leading to system harmonisation for extending HELP to other basins 
points and to transform these changes into business opportunities for the stakeholders. The research insights obtained from assessing these pressure points would be more worthwhile if it were targeted towards resolving the issues encountered in particular regions. A key objective of this approach is to establish Regional Irrigation Business Partnerships (RIBPs) to capture the production and environmental gains from research by improving the management of regional irrigation systems and to market these benefits to irrigation and environmental stakeholders.

A key element of the system harmonisation approach that can bring stakeholders together is that irrigation generates a myriad of benefits which are not confined to the irrigators or sector only. Rather these accrue to others sectors within and beyond the catchment and can be measured through multiplier effects. This generates widely shared benefits for the community as a whole and can serve as magnet to attract shared investments to harness these benefits. The non-tradable or social benefits such as those from enhanced environmental security, say in developing countries, and community cohesion can be converted into business opportunity through community enterprise investments financed by government/business entities based on corporate social responsibility and good governance principles (Gutman, 2007 and Hamann, 2004).

The System Harmonisation Framework thus involves an allencompassing approach that combines research and business principles to achieve productive and environmental improvements at the catchment level, and thus extending the HELP concept beyond its current domain.

\section{Conclusions}

The HELP initiative has proved to be of widespread interest around the world, North and South, with a significant number of proposals received from outside the hydrological research community. The demonstration and operational basins are practising many aspects of good water governance and can share best practice experience with other basins. Proposed and evolving basins are benefiting from international peer review and encouragement.

The system harmonisation framework can provide practical means to implement HELP concepts as it involves an all-encompassing approach that combines research and business principles to achieve productive and environmental improvements at various scales in a catchment context.

The framework involves 5 feasibility steps including 3 research components and a business analysis component. The research components comprise:

- Analysis and characterisation of hydrological systems

- Water productivity, markets and ecosystem services

- Mechanisms and processes for change.
While the business component is based on the formation of Regional Irrigation Business Partnerships to explore and implement opportunities for improved productive and/or environmental outcomes through changes in water management, a quest for gains is the common thread linking different stakeholders. Most importantly, members of the RIBP will have developed a shared vision to seize competitive commercial opportunities through technological innovation and improved environmental outcomes. The proposed interventions and actions must constitute viable business propositions in that they are financed on a business model approach and offer rewards to shareholders through new value added to the use of available water resources.

\section{Acknowledgements}

The author acknowledges the funding support by the Cooperative Research Centre for Irrigation Futures as the Leader of the System Harmonisation Program and contributions through his work at CSIRO and the Charles Sturt University, Australia.

\section{References}

BONNELL JE and KOONTZ TM (2007) Stumbling forward: The organizational challenges of building and sustaining collaborative watershed management. Soc. Nat. Resour. 20 153-167.

FALKENMARK M (2004) Towards integrated catchment management: Opening the paradigm locks between hydrology, ecology and policy-making. Special Volume on Hydrology for the Environment Life and Policy. Water Resour. Dev. 20 (3) 275-282.

GIBBONS M, LIMOGES H, NOWOTNY H SCHWARTZMAN S, SCOTT P and TROW M (1994) The New Production of Knowledge: The Dynamics of Science and Research in Contemporary Societies. Sage Publications, London.

GUTMAN P (2007) Ecosystem services: Foundations for a new ruralurban compact. Ecol. Econ. 62 383-387.

HAMANN R (2004) Corporate social responsibility, partnerships, and institutional change: The case of mining companies in South Africa. Nat. Resour. Forum 28 278-290.

INTERNATIONAL HYDROLOGICAL PROGRAMME (2001) Technical Documents in Hydrology, No $44 \backslash$ The Design and Implementation Strategy of the HELP Initiative. UNESCO, Paris.

KHAN S (2004) Integrating hydrology with environment, livelihood and policy issues - the Murrumbidgee Model. Special Volume on Hydrology for the Environment Life and Policy. Water Resour. Dev. 20 (3) 415-429.

KHAN S, MALANO HM and DAVIDSON B (2008) System harmonisation: a framework for applied regional irrigation business planning. Wiley J. Irrig. Drain. Published Online: Jun 132008 (DOI: 10.1002/ ird.382). http://www3.interscience.wiley.com/journal/77003202/ home?CRETRY=1\&SRETRY $=0$. 